\section{Visual function following neurosurgical optic nerve decompression for compressive optic neuropathy}

TJ Sleep ${ }^{1}$, PR Hodgkins' ${ }^{1}$ S Honeybul², G Neil-Dwyer², D Lang ${ }^{2}$ and B Evans ${ }^{3}$
Abstract

Aims To assess the course of visual function after neurosurgical decompression of the optic nerve during resection of intracranial tumours. To obtain information that may be used to counsel patients.

Methods A retrospective review of the acuity and visual fields of 27 patients undergoing neurosurgical decompression of 36 optic nerves in a regional neurosurgical centre. Two groups were considered, those undergoing craniotomy for sphenoid wing meningioma en plaque, and those undergoing an extended transbasal approach to intracranial tumours. Results At the last follow-up (1-97 months), improvement in acuity was seen in $47 \%$ of eyes with decompressed nerves. One-third of these showed late improvement, and twothirds showed immediate improvement. In total, $20 \%$ of eyes had worse acuity at the last follow-up compared with preoperative values, just under one-third of these showed late deterioration, and the remainder showed immediate deterioration. In total, $33 \%$ of eyes achieved acuities equal to those recorded preoperatively, $6 \%$ improving to this level postoperatively.

Conclusions The majority of eyes in this study maintained or improved acuity after decompression. A proportion of eyes continue to improve after surgery, and a proportion deteriorate. There is no relation between duration of preoperative symptoms or the level of preoperative acuity and the change in acuity achieved.

Eye (2003) 17, 571-578. doi:10.1038/

sj.eye. 6700439

Keywords: optic nerve decompression; intracranial tumours; visual function

\section{Introduction}

Visual problems are often the presenting symptom of intracranial tumours, particularly those originating from the sphenoid wing or the region of the optic chiasm. ${ }^{1}$ Direct compression of the optic nerve, infiltration of the nerve by tumour, or elevation of intracranial pressure can cause a reduction in visual acuity, colour vision, and visual field. At operation, tumour is usually seen to be intimately involved with the optic nerve and sheath on the side of the symptoms. Intracranial surgery involves decompression of the nerve, attempting to free it of tumour to enable recovery of function. Many case studies report a dramatic return of vision after operation for compressive optic neuropathies. $^{2,3}$

However, while an operation may macroscopically remove or debulk the tumour and free the optic nerves, experience shows that visual function may not return to the presymptomatic level. To date, there have been few series examining visual function after skull base surgery using craniofacial access to decompress surgically optic nerves compromised by tumour, making accurate prediction of visual prognosis difficult. ${ }^{4,5}$ Patients are currently told that stabilisation of acuity is the aim of surgery, with any improvement being a bonus. This study was designed to assess what changes in visual function, in this study measured by visual acuity and visual fields, can be expected after these intracranial decompression procedures.

Patients, materials, and methods

The clinical records of two series of patients were examined retrospectively. All patients had
${ }^{1}$ Department of

Ophthalmology

Southampton General

Hospital

Southampton, UK

${ }^{2}$ Department of

Neurosurgery

Southampton General

Hospital

Southampton, UK

${ }^{3}$ Department of Oral and Maxillofacial Surgery

Southampton General

Hospital Southampton, UK

Correspondence:

TJ Sleep

Southampton Eye Unit

Southampton General

Hospital

Tremona Road

Southampton SO16 6YD

UK

Tel.: +442380777 222 x 9004

Fax: + 442380794120

Email: tamsinsleep@

doctors.org.uk

Received: 18 July 2002

Accepted in revised form: 1 November 2002 
been referred to the regional Neurosurgical centre, and were primarily under the care of the Neurosurgical and Maxillofacial Surgery departments.

Group 1 consists of 12 consecutive patients with sphenoid wing meningioma en plaque undergoing 14 operations for tumour resection between 1991 and 1998. All of these patients transpired at the time of surgery to require optic nerve decompression as part of the surgical debulking. Meningiomas en plaque are rare, slowgrowing tumours that form a thin layer closely following the contours of the inner table of the skull. They promote extensive, disproportionate amounts of bony hyperostosis, which produce the clinical signs and symptoms. This group of tumours is defined more by its biological behaviour than by its histological appearance. ${ }^{6}$ This series of patients all had disease involving the sphenoid wing. In some cases this had extended into the orbital roof (seven patients), the middle fossa (eight patients), the cavernous sinus (three patients), the supraorbital rim (one patient), the infratemporal fossa (two patients), and the intra- and extraconal orbital tissue (four patients). Consequently, at the time of surgery patients underwent optic nerve and optic canal decompression, resection of the lateral wall and roof of the orbit, resection of the supraorbital rim, decompression of the superior orbital fissure plus resection of intra- and extraconal tumour as required. A transzygomatic approach was used, which gives wide exposure of the lateral wall of the orbit and the floor of the middle fossa.

The 15 patients in group 2 underwent resections including optic nerve decompression, via an extended transbasal approach ${ }^{7}$ for a variety of tumours, between 1993 and 1999. In total, 11 patients required intradural surgery, and four patients required extradural surgery. These patients were not consecutive, but were selected because their presenting symptom of visual disturbance was felt to be a result of compression of the afferent visual system and the object of their surgery was optic nerve decompression. This group was chosen as an easily identifiable group of patients having undergone optic nerve decompression.

In all cases, visual acuities and visual fields were measured preoperatively and at postoperative visits. Follow-up ranged from 1 to 97 months (mean follow-up 27 months). The presenting symptoms, and preoperative visual acuity and fields were recorded. Postoperatively, visual acuities were noted for the duration of the patients' follow-up, and visual fields, where recorded, were also examined. For the purpose of analysis, acuity was considered to have changed when there was a change of one line or more in the recorded level of Snellen acuity. Visual fields were recorded using Goldman perimetry throughout. Fields were considered to have changed when there was an expansion or constriction of more than $15^{\circ}$ of the field, over three or more clock hours.

\section{Results}

\section{Presentation-group 1}

In all, 12 patients with sphenoid wing meningioma en plaque underwent 14 operations during the period 1991-1999, patients 7 and 8 each having two operations for recurrent tumour. These were the only recurrences in the group. Patients 1 and 8 required adjuvant radiotherapy. The presentation prior to each operation is considered $(n=14)$. Eight of the 14 presentations (57\%) had unilateral blurred or decreased vision as one of the main presenting symptoms (varying from $6 / 5$ vision to perception of light only). At two presentations (14\%), patients also complained of visual field loss, or had visual field loss noted by an optometrist. No patients had bilateral symptoms. Other indications for surgery included proptosis (11 patients), temporal or eyelid swelling (seven patients), and pain (five patients). One patient (patient 9) had visual failure alone as an indication for surgery.

On examination in the clinic, decreased acuity was found at nine of 14 presentations (64\%). Visual field defects were present in eight $(57 \%)$, with the most common defect being inferior loss, either peripheral or extending centrally (21\%). The duration of symptoms before presentation to the neurosurgeon ranged from 1 week to 18 years (mean 32 months, median 12 months) (Table 1). No significant correlation was found between the duration of symptoms and the degree of visual loss, measured in lines of Snellen acuity below 6/4 (Spearman rank correlation).

\section{Presentation-group 2}

In total, 15 patients underwent an extended transbasal approach to a tumour compressing the optic nerves or optic nerves and chiasm. A single patient (patient 2) required adjuvant radiotherapy. Eight patients had meningiomas (53\%), two had chordomas (13\%), two had pituitary tumours (13\%) and, of the remaining three patients, one had a craniopharyngioma, one a schwannoma, and one fibrous dysplasia. At presentation $11(73 \%)$ patients complained of decreased vision $(73 \%)$ and seven (47\%) had unilateral symptoms. One of these patients also had a symptomatic visual field defect, and a 12th patient had no blurring, but noticed field defects alone. Patient 7 presented with epistaxis, but was found, on examination, to have decreased acuity in the right eye when compared to the optician's records. 
Table 1 Presenting symptoms and signs in cases with sphenoid wing meningioma requiring optic nerve decompression

\begin{tabular}{|c|c|c|c|c|c|c|c|c|c|c|}
\hline \multirow[t]{2}{*}{ No. } & \multirow[t]{2}{*}{ Age } & \multirow{2}{*}{$\begin{array}{l}\text { Extent of tumour } \\
\text { (in addition to sphenoid wing) }\end{array}$} & \multicolumn{3}{|c|}{ Presenting symptoms } & \multirow[t]{2}{*}{ Symptoms } & \multicolumn{2}{|c|}{ Preop VA } & \multicolumn{2}{|c|}{ Preop VF } \\
\hline & & & Blurring & $V F$ defect & Other & & $R$ & $L$ & $R$ & $L$ \\
\hline 1 & 61 & Cavernous sinus & No & No & $\begin{array}{l}\text { Proptosis, } \\
\text { pain }\end{array}$ & 24 months & $6 / 6$ & $3 / 36$ & Full & Full \\
\hline 2 & 65 & $\begin{array}{l}\text { Orbital roof, cavernous sinus, } \\
\text { intra and extraconal }\end{array}$ & Yes, $\mathrm{R}$ & Yes, $\mathrm{R}$ & Proptosis & 24 months & $6 / 18$ & $6 / 6$ & IT defect & Full \\
\hline 3 & 50 & $\begin{array}{l}\text { Orbital roof/canal, middle } \\
\text { fossa, cavernous sinus, chiasm, } \\
\text { ant clinoid }\end{array}$ & Yes, L & Yes, L & Pain & 36 months & $6 / 5$ & $6 / 6$ & Full & $\begin{array}{l}\text { Inferior } \\
\text { arcuate }\end{array}$ \\
\hline 4 & 37 & Temporal fossa, middle fossa & Yes, $\mathrm{R}$ & No & $\begin{array}{l}\text { Proptosis, } \\
\text { pain }\end{array}$ & 12 months & $6 / 12$ & $6 / 9$ & Full & Full \\
\hline 5 & 51 & Orbital roof, middle fossa & Yes, $\mathrm{R}$ & No & Proptosis & 24 months & $6 / 9$ & $\mathrm{HM}$ & Full & - \\
\hline 6 & 47 & Middle fossa & No & No & Proptosis & 10 months & $6 / 4$ & $6 / 6-$ & Full & Full \\
\hline 7 & 38 & Orbital roof, middle fossa & Yes, L & No & $\begin{array}{l}\text { Diplopia, } \\
\text { proptosis }\end{array}$ & 36 months & $6 / 6$ & $6 / 9$ & Full & Full \\
\hline $7 a$ & 47 & Orbital roof, middle fossa & Yes, $\mathrm{R}$ & No & Proptosis & - & $6 / 36$ & $6 / 4$ & $\begin{array}{l}\text { Inferior } \\
\text { defect }\end{array}$ & Full \\
\hline 8 & 32 & $\begin{array}{l}\text { Middle fossa, orbital roof, } \\
\text { intra and extraconal, orbital } \\
\text { apex, temporal muscle }\end{array}$ & Yes, $\mathrm{R}$ & No & Pain & 6 months & $\mathrm{CF}$ & $6 / 4$ & $\begin{array}{l}\text { Central } \\
\text { defect }\end{array}$ & Full \\
\hline $8 a$ & 35 & $\begin{array}{l}\text { Lateral orbit, IOF, } \\
\text { infratemporal fossa }\end{array}$ & No & No & $\begin{array}{l}\text { Proptosis, } \\
\text { headache }\end{array}$ & 6 months & $6 / 5$ & $6 / 4$ & $\begin{array}{l}\text { Central } \\
\text { defect }\end{array}$ & Full \\
\hline 9 & 51 & Optic nerve & Yes, L & No & No & 1 week & $6 / 6$ & PL & Full & $\begin{array}{l}\text { Inferior } \\
\text { defect }\end{array}$ \\
\hline 10 & 65 & $\begin{array}{l}\text { Orbital roof, orbital fascia, } \\
\text { middle fossa }\end{array}$ & No & No & Proptosis & 18 years & $6 / 5$ & $6 / 5$ & $\begin{array}{l}\text { Slight } \\
\text { constriction }\end{array}$ & Full \\
\hline 11 & 40 & $\begin{array}{l}\text { Orbital roof, middle fossa, } \\
\text { infratemporal fossa }\end{array}$ & No & No & $\begin{array}{l}\text { Proptosis, } \\
\text { diplopia }\end{array}$ & 14 months & $6 / 5$ & $6 / 5$ & Full & Full \\
\hline 12 & 49 & $\begin{array}{l}\text { Orbital roof, supraorbital } \\
\text { rim, frontal bone }\end{array}$ & No & No & $\begin{array}{l}\text { Swelling, } \\
\text { pain }\end{array}$ & 10 months & $6 / 6$ & $6 / 6$ & Full & Full \\
\hline
\end{tabular}

On examination in the clinic, decreased acuity was found in 13 of the 15 patients $(87 \%)$, with bilateral reduction of visual acuity in nine $(60 \%)$. Presenting visual acuities varied from $6 / 6$ to perception of light. Visual field defects were present in 12 patients (80\%), and five patients had bilateral visual field loss (33\%). Homonymous defects were the most common (three patients, one homonymous hemianopia, and two homonymous quadrantanopias). One patient had a bitemporal hemianopia.

The duration of symptoms before presentation ranged from 3 months to 14 years (mean 25 months, median 6 months) (Table 2). No significant relation was found between the duration of symptoms and the severity of visual loss (Spearman rank correlation).

\section{Postoperative visual acuity-group 1}

Three operations involved decompression of the left optic nerve, and 11 involved decompression of the right. No patients required bilateral decompression. Visual acuity was recorded at its best postoperative level (ie the best level of acuity recorded at any outpatient visit), and at the level documented at the last outpatient visit (Table 3). Late improvement or deterioration is defined as being a change noted at the last follow-up visit as compared with immediately pre- and postoperatively (9-97 months in group 1).

Analysing the best recorded visual acuities at any point postoperatively, $50 \%$ of cases had an improvement in acuity on the side of decompression $(n=7) ; 36 \%$ of cases had no change in acuity $(n=5)$, and two cases had worse vision $(14 \%)$ on the decompressed side.

At the last follow-up, 36\% of cases showed an improvement in acuity compared with preoperative levels $(n=5)$. Of these, four $(28.5 \%)$ had shown an immediate improvement (within 2 months of surgery), and one showed a late improvement, that is, the acuity was improved at the last recorded follow-up (7\%). The amount of improvement ranged from 1 to 8 Snellen lines (mean 2.5 lines, median 2 lines).

In total, $36 \%$ of cases had worse acuity at the last follow-up compared with preoperative levels $(n=5)$. Of these, two (14\%) had been worse immediately postoperatively, and three $(21.5 \%)$ had shown late 
Table 2 Presenting symptoms and signs in patients requiring transbasal surgery and optic nerve decompression

\begin{tabular}{|c|c|c|c|c|c|c|c|c|}
\hline \multirow[t]{2}{*}{ Patient No. } & \multirow[t]{2}{*}{ Age } & \multirow[t]{2}{*}{ Pathology } & \multirow{2}{*}{$\begin{array}{l}\text { Presenting } \\
\text { symptoms }\end{array}$} & \multirow[t]{2}{*}{ Dur $S x$} & \multicolumn{2}{|c|}{ Preop VA } & \multicolumn{2}{|c|}{ Preop VF } \\
\hline & & & & & $R$ & $L$ & $R$ & $L$ \\
\hline 1 & 43 & $\begin{array}{l}\text { Chordoma (sphenoid sinus, } \\
\text { nasophaynx) }\end{array}$ & $\begin{array}{l}\text { Blurring RE, } \mathrm{R} \\
\text { VIIn palsy }\end{array}$ & 7 months & $3 / 9-$ & $6 / 4$ & Inferior defect & Full \\
\hline 2 & 30 & Chordoma (chiasm, o nerve) & Blurring LE & 3 months & $6 / 12$ & PL & Central scotoma & Full \\
\hline 3 & 79 & Meningioma (basal, R o.n.) & Blurring LE & 6 months & $6 / 24$ & PL & $\begin{array}{l}\mathrm{R} \text { homonymous } \\
\text { Hemianopia }\end{array}$ & \\
\hline 4 & 71 & Meningioma (frontal, L o.n.) & $\begin{array}{l}\text { L VIIn palsy, } \\
\text { proptosis }\end{array}$ & 14 year & $6 / 9$ & $6 / 12$ & Full & Full \\
\hline 5 & 73 & $\begin{array}{l}\text { Meningioma } \\
\text { (frontal, orbit, L o.n.1) }\end{array}$ & Blurring LE & - & NPL & $6 / 5$ & - & UT loss \\
\hline 6 & 63 & Granular pituitary tumour & Bilat VF defects & 3 months & $6 / 9-$ & $6 / 9-$ & $\begin{array}{l}\text { Left lower } \\
\text { quadrantinopia }\end{array}$ & \\
\hline 7 & 39 & Schwannoma (skull base) & Epistaxis & 24 months & $6 / 9$ & $6 / 6-$ & Full & Full \\
\hline 8 & 70 & Meningioma (subfrontal) & Blurring BE & 5 months & $6 / 18$ & $6 / 36$ & $\begin{array}{l}\text { Right inferior } \\
\text { quadrantinopia }\end{array}$ & \\
\hline 9 & 65 & Meningioma (suprasellar) & Blurring BE & - & PL & $6 / 12$ & 1 & Full \\
\hline 10 & 37 & Fibrous dysplasia (clivus) & Blurring RE & 12 months & $6 / 9$ & $6 / 6$ & Full & Full \\
\hline 11 & 14 & Craniopharyngioma & $\begin{array}{l}\text { Vomiting, } \\
\text { headache }\end{array}$ & 12 months & $6 / 9$ & $6 / 9$ & Temporal defect & Full \\
\hline 12 & 46 & Pituitary adenoma & Blurring RE & 10 months & $6 / 6$ & $6 / 5$ & ST loss & ST loss \\
\hline 13 & 46 & Meningioma (sellar, optic tract) & Poor vision & 5 months & $\mathrm{HM}$ & $\mathrm{HM}$ & Full & $\begin{array}{l}\text { Superior } \\
\text { defect }\end{array}$ \\
\hline 14 & 5 & Meningioma (suprasellar) & $\begin{array}{l}\text { Poor vision, } \\
\text { nystagmus }\end{array}$ & 60 months & NPL & Poor & - & \\
\hline 15 & 57 & Meningioma (frontal) & $\begin{array}{l}\text { Blurring and } \\
\text { VF defect LE }\end{array}$ & 17 months & $6 / 5$ & $6 / 18$ & Full & $\begin{array}{l}\text { Inferior } \\
\text { defect }\end{array}$ \\
\hline
\end{tabular}

Table 3 Change in visual function after surgery for sphenoid wing meningioma

\begin{tabular}{|c|c|c|c|c|c|c|c|c|c|c|c|}
\hline \multirow[t]{2}{*}{$\begin{array}{l}\text { Patient } \\
\text { No. }\end{array}$} & \multirow[t]{2}{*}{$\begin{array}{l}\text { Side decom- } \\
\text { pressed }\end{array}$} & \multicolumn{2}{|c|}{$\begin{array}{l}\text { Postop VA at last FU } \\
\text { (best postop VA of decom- } \\
\text { pressed side in brackets) }\end{array}$} & \multicolumn{2}{|l|}{$\begin{array}{l}\text { Postop } \\
\text { VF }\end{array}$} & \multicolumn{2}{|c|}{$\begin{array}{c}\text { Change in VA } \\
\text { at last FU }\end{array}$} & \multirow{2}{*}{$\begin{array}{c}\text { Change of } \\
\text { decompressed } \\
\text { side in Snellen } \\
\text { lines }\end{array}$} & \multicolumn{2}{|c|}{$\begin{array}{l}\text { Change } \\
\text { in VF }\end{array}$} & \multirow[t]{2}{*}{$\begin{array}{l}\text { Duration } \\
\text { of FU }\end{array}$} \\
\hline & & $R$ & $L$ & $R$ & $L$ & $R$ & $L$ & & $R$ & $L$ & \\
\hline 1 & Left & $6 / 6$ & $3 / 24(3 / 24)$ & Full & Full & ISQ & Better & +1 & ISQ & ISQ & 44 months \\
\hline 2 & Right & $6 / 18(6 / 6)$ & $6 / 5$ & IT defect & Full & ISQ & ISQ & 0 & ISQ & ISQ & 58 months \\
\hline 3 & Right & $6 / 5(6 / 5)$ & $6 / 5$ & Full & $\begin{array}{l}\text { Inferior } \\
\text { defect }\end{array}$ & ISQ & Better & 0 & ISQ & Better & 24 months \\
\hline 4 & Right & PL (6/18) & $6 / 9$ & Hemianopia & & Worse & ISQ & -7 & Worse & Worse & 21 months \\
\hline 5 & Right & $6 / 5(6 / 5)$ & $\mathrm{HM}$ & Full & - & Better & ISQ & +2 & ISQ & ISQ & 9 months \\
\hline 6 & Left & $6 / 4$ & $6 / 5(6 / 5)$ & Full & Full & ISQ & Better & +1 & ISQ & ISQ & 16 months \\
\hline 7 & Right & $6 / 9(6 / 6)$ & $6 / 9$ & Full & Full & Worse & ISQ & -1 & ISQ & ISQ & 97 months \\
\hline $7 \mathrm{a}$ & Right & $6 / 18(6 / 18)$ & $6 / 4$ & $\begin{array}{l}\text { Inferior } \\
\text { defect }\end{array}$ & Full & Better & ISQ & +2 & ISQ & ISQ & 15 months \\
\hline 8 & Right & $6 / 5(6 / 4)$ & $6 / 4$ & $\begin{array}{l}\text { Central } \\
\text { defect }\end{array}$ & Full & Better & ISQ & +8 & Better & ISQ & 42 months \\
\hline $8 \mathrm{a}$ & Right & $6 / 6(6 / 4)$ & $6 / 4$ & $\begin{array}{l}\text { Central } \\
\text { defect }\end{array}$ & Full & Worse & ISQ & -1 & Better & ISQ & 20 months \\
\hline 9 & Left & $6 / 5$ & NPL $(6 / 60)$ & Full & - & Better & Worse & -1 & ISQ & Worse & 28 months \\
\hline 10 & Right & $6 / 5(6 / 5)$ & $6 / 5$ & Full & Full & ISQ & ISQ & 0 & Better & ISQ & 50 months \\
\hline 11 & Right & $6 / 6(6 / 6)$ & $6 / 5-$ & $\begin{array}{l}\text { Inferior } \\
\text { defect }\end{array}$ & Full & Worse & ISQ & -1 & Worse & ISQ & 12 months \\
\hline 12 & Right & $6 / 6(6 / 6)$ & $6 / 6$ & Full & Full & ISQ & ISQ & 0 & ISQ & ISQ & 85 months \\
\hline
\end{tabular}

deterioration. The amount of deterioration ranged from 1 to 7 Snellen lines (mean 2.2 lines, median 1 line).
In total, $28 \%$ had no change in acuity $(n=4)$; one of these patients $(7 \%)$ had initially been better immediately postoperatively. 
The length of follow-up ranged from 9 to 97 months (average 37 months).

Two patients had repeat operations (patients 7 and 8). Patient 7 lost 1 line of acuity after the first operation, and after the second gained 2 lines. Patient 8 gained 8 lines after the first operation, and after the second lost 1 line, although the acuity was still good, at 6/6.

At the last follow-up, the nonoperated side either retained acuity at preoperative levels $(86 \%, n=12)$ or improved by 1 Snellen line $(14 \%, n=2)$ (Table 5 ). There appears to be no significant correlation in this series between the duration of symptoms or the level of preoperative vision and the degree of postoperative change in vision (Spearman rank correlation).

\section{Postoperative visual fields-group 1}

On the operated side, visual fields had improved at the last clinic follow-up in three of 14 cases (21.5\%) and were stable in eight $(57 \%)$. Deterioration was seen in three cases $(21.5 \%)$. Both of these cases previously had full fields: one developed a hemianopia postoperatively, and one developed an inferior field defect on the operated side.

On the nonoperated side, 12 cases still had full fields (86\%). One patient had an improvement in a preoperative inferior defect, and one was worse (the patient who developed the hemianopia).

\section{Postoperative visual acuity-group 2}

Nine patients in this group required bilateral optic nerve decompression, three had the left nerve only decompressed, and one had the right only decompressed. In two patients' records, the side decompressed was not recorded, but their results are included in Tables 2 and 4 for interest. In total, 22 eyes were therefore considered in the analysis. Visual acuity was again recorded at its best level postoperatively, and at the level noted at the last clinic visit. The average length of follow-up was 31 months (range 1-80 months). At best, visual acuity in eyes with surgically decompressed nerves was better in 10 of 22 eyes (45\%), maintained at preoperative levels in seven (32\%) and reduced in five $(23 \%)$.

At the time of the last follow-up, nine eyes had improved acuity $(41 \%)$. Of these nine eyes, five had an immediate improvement $(23 \%)$, and four a late change $(18 \%)$. It should be noted that the follow-up of one of the eyes with immediate and sustained improvement is restricted to 1 month. Improvement ranged from 1 to 4 Snellen lines of acuity (mean 1.7 lines, median 1 line).

Table 4 Change in visual function after optic nerve decompression during transbasal tumour resection

\begin{tabular}{|c|c|c|c|c|c|c|c|c|c|c|c|c|}
\hline \multirow[t]{2}{*}{$\begin{array}{l}\text { Patient } \\
\text { No. }\end{array}$} & \multirow[t]{2}{*}{$\begin{array}{l}\text { Side decom- } \\
\text { pressed }\end{array}$} & \multicolumn{2}{|c|}{$\begin{array}{l}\text { Postop VA at last FU } \\
\text { (best postop VA of decom- } \\
\text { pressed side in brackets) }\end{array}$} & \multicolumn{2}{|c|}{$\begin{array}{l}\text { Postop } \\
\text { VF }\end{array}$} & \multicolumn{2}{|c|}{$\begin{array}{c}\text { Change in VA } \\
\text { at last FU }\end{array}$} & \multicolumn{2}{|c|}{$\begin{array}{c}\text { Change of } \\
\text { decompressed } \\
\text { side in Snellen } \\
\text { lines }\end{array}$} & \multicolumn{2}{|c|}{$\begin{array}{l}\text { Change } \\
\text { in VF }\end{array}$} & \multirow[t]{2}{*}{$\begin{array}{l}\text { Duration } \\
\text { of FU }\end{array}$} \\
\hline & & $R$ & $L$ & $R$ & $L$ & $R$ & $L$ & $R$ & $L$ & $R$ & $L$ & \\
\hline 1 & Both & $6 / 36$ & $6 / 4$ & $\begin{array}{l}\text { Central } \\
\text { loss }\end{array}$ & Full & Worse & ISQ & -2 & 0 & Better & ISQ & 7 months \\
\hline 2 & Both & $\begin{array}{l}6 / 12 \\
(6 / 9)\end{array}$ & NPL & $\begin{array}{l}\text { Central } \\
\text { loss }\end{array}$ & - & ISQ & Worse & 0 & -1 & ISQ & Worse & 33 months \\
\hline 3 & Right & $6 / 36$ & $\mathrm{CF}$ & - & - & Worse & Better & -1 & +2 & - & - & $\begin{array}{l}1 \text { months- } \\
\text { lost to FU }\end{array}$ \\
\hline 4 & Left & $6 / 9$ & $6 / 12+$ & Full & Full & ISQ & Better & 0 & +1 & ISQ & ISQ & 13 months \\
\hline 5 & Left & NPL & $6 / 4$ & - & UT loss & ISQ & Better & 0 & +1 & ISQ & ISQ & 46 months \\
\hline 6 & Both & $6 / 6$ & $\mathrm{CF}(6 / 24)$ & $\begin{array}{l}\text { Temp } \\
\text { loss }\end{array}$ & $\begin{array}{l}\text { SN, ST, } \\
\text { IT loss }\end{array}$ & Better & Worse & +1 & -6 & Worse & Worse & 39 months \\
\hline 7 & Both & $6 / 6-$ & $6 / 5-$ & Full & Full & Better & Better & +1 & +1 & ISQ & ISQ & 46 months \\
\hline 8 & Both & $\begin{array}{l}6 / 9 \\
(6 / 6)\end{array}$ & 6/9 (6/6) & Full & Full & Better & Better & +2 & +4 & Better & Better & 25 months \\
\hline 9 & Left & NPL & $6 / 18$ & - & Temp loss & Worse & Worse & -1 & -1 & Worse & Worse & 36 months \\
\hline 10 & Both & $6 / 6$ & $6 / 6$ & Full & Full & Better & ISQ & +1 & 0 & ISQ & ISQ & 80 months \\
\hline 11 & $\begin{array}{l}\text { Not } \\
\text { known }\end{array}$ & NPL & $6 / 9-$ & - & ST defect & Worse & Worse & -9 & -1 & Worse & Worse & 3 months \\
\hline 12 & $\begin{array}{l}\text { Not } \\
\text { known }\end{array}$ & $6 / 4$ & $6 / 4$ & ST loss & ST loss & Better & Better & +2 & +1 & ISQ & ISQ & 4 months \\
\hline 13 & Both & HM & $\mathrm{HM}$ & Constricted & Constricted & ISQ & ISQ & 0 & 0 & ISQ & Better & 4 months \\
\hline 14 & Both & NPL & $\mathrm{HM}$ & - & - & ISQ & ISQ & 0 & 0 & - & - & 48 months \\
\hline 15 & Both & $6 / 6$ & $6 / 6$ & Full & IT loss & Worse & Better & -1 & +3 & ISQ & Better & 42 months \\
\hline
\end{tabular}


Six eyes (27\%) had worse acuity at the last follow-up. Of these, all but one showed immediate deterioration.

The mean decrease was 2 lines (range 1-6 lines, median 1 line).

Seven eyes had maintained acuity (32\%). All but one of these had stable vision postoperatively. One eye (4.5\%) had been immediately better, before decreasing again to the preoperative level.

Visual acuities on the nondecompressed side improved in one eye, by 2 lines. Visual acuity was maintained in two eyes, and worsened in one eye, by 1 Snellen line. In the patients where the side of decompression was not recorded, one patient had an improvement in acuity bilaterally, and one patient suffered postoperative bleeding and lost all vision in one eye, and 1 line of acuity in the other.

No significant correlation could be found between the duration of symptoms and the change in acuity postoperatively. Similarly, no significant relation could be found between the level of preoperative visual acuity and the postoperative change in acuity (Spearman rank correlation). There appears to be no difference in results between extradural or intradural approach during surgery, although the numbers involved are very small (four patients only with extradural surgery).

\section{Postoperative visual fields-group 2}

Postoperative Goldman visual fields were recorded in all but two patients, and their change at the last postoperative visit is reported. Of the 19 recorded fields from decompressed sides, 11 fields were unchanged $(58 \%)$, five were improved (26\%), and three were worse $(16 \%)$. Of these three, one patient developed unilateral temporal field loss after meningioma resection, and one patient had an extension of a homonymous quadrantanopia to a bitemporal hemianopia with nasal loss after resection of a granular pituitary tumour. Fields on the unoperated side were maintained in two eyes, and were worse in one patient, whose vision in that eye had deteriorated from PL to NPL.

\section{Combined results}

All decompressed nerves were considered $(n=36)$. At best, visual acuity was improved in $47 \%$, maintained in $33 \%$, and worse in $20 \%$. At the latest follow-up, improvement was seen compared with preoperative values in $38 \%$ of decompressed sides, $25 \%$ showing immediate and sustained improvement, and $13 \%$ showing late improvement. In total, $31 \%$ of eyes had worse acuity at the last follow-up compared to preoperative values: $20 \%$ suffering immediate deterioration and $11 \%$ showing late deterioration. In total, $31 \%$ of eyes had acuities at the last follow-up equal to those recorded preoperatively; $6 \%$ had initially been better postoperatively before reaching this level at the last follow-up. No significant relation could be found between the change in acuity achieved after decompression and the duration of the symptoms preoperatively. Similarly, there was no significant correlation found between the preoperative vision, and the change in acuity that was achieved postoperatively (Spearman rank correlation).

Visual fields were improved in $24 \%$, maintained in $61 \%$, and showed deterioration in $15 \%$ of eyes with decompressed optic nerves.

\section{Discussion}

En plaque meningiomas and other intracranial tumours frequently present with visual disturbance secondary to a compressive optic neuropathy that may be multifactorial in origin. Direct compression, indirect compression by other intracranial structures, infiltration of the nerve and nerve sheath, and ischaemia may all play a part. ${ }^{4}$ Loss of visual acuity is the most frequent complaint, with visual field loss, while frequently found, remaining largely asymptomatic in our series. Visual field loss might be expected more frequently than was found in this series, if optic nerve compression is thought to explain the reduced acuity. It is possible that the field testing was inadequately sensitive, or in some cases inaccurately recorded because of poor acuity. The object of this paper is to report the visual outcomes of a series of 36 optic nerve decompressions undertaken at the time of surgery to debulk or remove intracranial tumours.

In our series only $36 \%$ of patients with sphenoid wing meningioma en plaque at the last follow-up, and $41 \%$ of decompressed nerves in the group requiring a transbasal approach had improved visual acuity. An additional 28\% in group 1, and 32\% in group 2 maintained their acuity, but a reduction of acuity was seen in more than $20 \%$ of eyes in both groups. Deterioration may be seen immediately postoperatively or may be late in onset. Similarly, postoperative improvement may be immediate, or late. Deterioration in visual acuity was occasionally very severe; for example, patients 6 and 11 in group 2 deteriorated from 6/9 to CF and NPL, respectively, in one eye. Patient 4 in group 1 also deteriorated from $6 / 12$ to PL on the operated side.

It is interesting that there was no correlation between the duration of the visual symptoms, and therefore presumably the duration of the compression, and the amount of postoperative recovery in our series or in others. ${ }^{4}$ It is possible that a larger sample would show such a relation, but in our series, large changes in acuity were relatively rare, the mean change being less than two 
lines in Snellen visual acuity. Presenting acuities were better in group 1 than group 2, but in neither group did the presenting acuity correlate with the change in acuity achieved.

One patient in group 1 did show a dramatic improvement from CF to 6/5 vision; he had been symptomatic for 6 months. This is at odds with the theory that dramatic responses are usually seen in patients where there has been a rapid loss of vision. ${ }^{8}$ Indeed, the one patient with rapid visual loss in this series (number 9, group 1) suffered a deterioration in vision postoperatively. There is little in this study to support the idea that prompt decompression is necessary for improvement in visual function.

Our relatively large series includes a variety of intracranial pathologies and approaches, and all operations involved tumour resection with optic nerve or optic nerve and chiasmal decompression. The variety of pathologies, while allowing examination of an increased number of cases, does make it difficult to compare results directly between the two groups, and may decrease the validity of the combined results. In addition, the series is retrospective, and as such the assessment of visual function is limited to examining the visual acuities and visual fields recorded at outpatient visits. It is not possible to assess to what extent direct compression, infiltration of the nerve, or optic atrophy contributed to the preoperative visual loss seen. It is important to appreciate that Snellen acuity is recognised increasingly as only a small part of visual function. Ideally, optic nerve appearance, colour vision, contrast sensitivity, and visual evoked responses would also be included in the assessment. This may be the basis of a future prospective study.

Case reports may lead us to believe that a dramatic improvement in acuity following prompt decompression is to be expected. ${ }^{2,3}$ However, there are few series of cases of intracranial decompression in the literature to support this. One series in 1975 of cases with mixed, mostly pituitary pathologies showed rapid recovery of acuity and central field measured with a hand-held perimeter in six of 11 patients. ${ }^{4}$ However, the follow-up was the length of the hospital stay only (up to 15 days). A series of 15 eyes requiring optic canal decompression via craniotomy reported improvements in visual acuity and visual field in $90 \%$, with follow-up times of up to 87 months. ${ }^{5}$ This series contained mixed pathologies, only six of which were tumours requiring resection. Optic nerve decompression is currently receiving increasing amounts of attention, as there are no standard treatment protocols to guide the management of either compressive or traumatic optic neuropathy. Recently, retrospective series of extracranial optic nerve decompressions via the transethmoidal route report high rates of visual improvement postoperatively, and the authors suggest this technique as being minimally invasive. ${ }^{9,10}$ However, many pathologies require an intracranial approach, with optic nerve decompression forming only a part of the whole surgical procedure, and it may not be appropriate to extrapolate these results to predict the results of intracranial surgery.

During surgery, while the tumour can often be successfully debulked, and the optic nerve freed macroscopically, it is difficult to know exactly how much decompression of the nerve has been achieved. If the tumour has infiltrated the nerve or nerve sheath, or is particularly intimately associated with it, it will be impossible to achieve complete clearance. In addition, permanent damage may already have occurred, with compression having caused interruption of axonal flow, demyelination and ischaemia of the nerve. ${ }^{11}$ As a result, relieving compression may not cause an improvement in acuity. Improvement in vision may in part be explained by the relief both of direct compression and compression secondary to increased intracranial pressure, possibly allowing relief of conduction block with resumed axonal flow acutely and, in the longer term, remyelination and thus continued improvement in function. ${ }^{4}$

The deterioration seen is likely to have several aetiologies. Surgical complications such as haemorrhage occasionally cause profound visual loss, as in one of our patients, and direct manipulation of the nerve or surgical trauma may also cause damage. Residual or recurrent tumour is a major factor when the results at the last follow-up are considered, and a decision about reoperation may be based on deterioration in acuity or field. Recurrent tumour that was considered significant enough to merit further surgical intervention was seen in two of the patients in group 1 only. It is also important to remember that any concurrent radiotherapy may cause radiation-induced optic neuropathy, particularly if total doses are approaching 40-50 Gy. Optic neuropathy has also been reported after uncomplicated decompressive craniotomy, possibly secondary to hypoperfusion of the prelaminar portion of the optic nerve. This generally shows a poor recovery, but is felt to be rare. ${ }^{12}$

In conclusion, this study suggests that maintenance or improvement in visual acuity and visual field is seen ultimately in approximately $70 \%$ of eyes after intracranial decompression of the optic nerve as part of a larger surgical procedure. Improvement may occur immediately after surgery, but a small proportion of eyes go on to improve over time. Similarly, of the remaining eyes that deteriorate after surgery, most deteriorate immediately, but a small proportion will deteriorate later. 
There is no evidence in the study to support the fear that early decompression, when visual acuities are reasonably good, is more detrimental to vision than late decompression. This may be particularly relevant in cases of sphenoid wing meningiomas, where cosmesis may be improved by early surgery without necessarily sacrificing the visual function.

\section{References}

1 Miller NR. Neuro-ophthalmologic topographic diagnosis of tumours and related conditions. In: Miller NR, Walsh FB (eds). Walsh and Hoyt's Clinical Neuro-ophthalmology, 4th ed. Baltimore: Williams \& Wilkins, 1988; pp 1137-1242.

2 Kurimoto M, Endo S, Onizuka K, Akai T, Takaku A. Extradural optic nerve decompression for fibrous dysplasia with a favourable visual outcome. Neurol Med Chir 1996; 36(2): 102-105.

3 Weisman JS, Hepler RS, Vinters HV. Reversible visual loss caused by fibrous dysplasia. Am J Ophthalmol 1990; 110: 244-249.

4 Kayan A, Earl CJ. Compressive lesions of the optic nerves and chiasm: pattern of recovery of vision following surgical treatment. Brain 1975; 98: 13-28.
5 Guyer DR, Miller NR, Long DM, Allen GS. Visual function following optic canal decompression via craniotomy. J Neurosurg 1985; 62(5): 631-638.

6 Honeybul S, Neil-Dwyer G, Lang DA, Evans BT, Ellison DW. Sphenoid wing meningioma en plaque: a clinical review. Acta Neurochir (Wein) 2001; 143(8): 749-757.

7 Honeybul S, Neil-Dwyer G, Lang DA, Evans BT, Weller RO, Gill J. The extended transbasal approach: a quantitative anatomical and histological study. Acta Neurochir (Wein) 1999; 141(3): 251-259.

8 Pennybacker J. The treatment of pituitary tumours. Proc $R$ Soc Med 1961; 54: 619-621.

9 Maurer J, Hinni M, Mann W, Pfeiffer N. Optic nerve decompression in trauma and tumour patients. Eur Arch Otorhinolaryngol 1999; 256: 341-345.

10 Li KK, Lucarelli MJ, Bilyk JR, Joseph MP. Optic nerve decompression for compressive neuropathy secondary to neoplasia. Arch Otolaryngol Head Neck Surg 1997; 123(4): 425-429.

11 Miller NR. Retrobulbar compressive optic neuropathies without optic disc swelling. In: Miller NR, Walsh FB (eds). Walsh and Hoyt's Clinical Neuro-ophthalmology, 4th ed. Baltimore:Williams \& Wilkins, 1988, pp 1137-1242.

12 Beck RW, Greenberg HS. Post-decompression optic neuropathy. J Neurosurg 1985; 63(2): 196-199. 